International Journal of Instruction

e-ISSN: 1308-1470 • www.e-iji.net

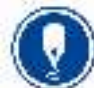

July $2021 \bullet$ Vol.14, No.3

p-ISSN: 1694-609X

pp. $999-1010$

Article submission code

20200805150235

Received: 05/08/2020

Revision: 09/02/2021
Accepted: 05/03/2021

OnlineFirst: 24/06/2021

\title{
Exploring the Relationship between Identity Orientation and Symptoms of Depression among Third Culture Kids college students ${ }^{1}$
}

\section{Hiba Habeeb}

Psychology Program, United Arab Emirates University, 201770092@uaeu.ac.ae

\author{
Abdalla A. R. M. Hamid \\ Prof., corresponding author, Department of Clinical Psycology, United Arab Emirates \\ University, ahamid@uaeu.ac.ae
}

\begin{abstract}
Third culture kids represent a significant portion of the population in the United Arab Emirates. However, little is known about the psychological problems that may be encountered by these kids. The third culture kids' problems that received adequate attention included relationship and identity problems, unresolved grief, and high rates of geographic relocation. The main objective of this study is to examine the incidence of depression and dimensions of identity orientation among third culture kids studying in college. A further objective is to examine the ability of the different identity orientations to predict symptoms of depression in this population. A total of 250 adult third culture kids living in the United Arab Emirates were chosen to take part in this study. The measures administered in this study were Beck's Depression Inventory (BDI-II) and the Aspects of Identity Questionnaire (AIQ IV-45). The results indicated that $27.2 \%$ of the participants reported moderate to severe depression. Concerning identity orientation, personal identity and relational identity orientations were the most extremely important to the respondents' sense of who they are, whereas social identity and collective identity orientations were the least extremely important. Stepwise multiple regression revealed that gender and social identity orientation significantly predicted depression. It is concluded that more work needs to be done for a better understanding of this group of adult third culture kids and the understanding of the difficulties they encounter. Moreover, professionals need to provide appropriate psychological help for this group.
\end{abstract}

Keywords: virtual simulation, web-based application, multimedia, teaching, learning

\footnotetext{
${ }^{1}$ This study was produced from the data of the master thesis.

Citation: Habeeb, H., \& Hamid, A. A. R. M. (2021). Exploring the relationship between identity orientation and symptoms of depression among third culture kids college students. International Journal of Instruction, 14(3), 999-1010. https://doi.org/10.29333/iji.2021.14358a
} 


\section{INTRODUCTION}

Persons who have spent the main part of their developmental years in foreign cultures are identified as third culture kids (TCKs). As a result, they demonstration some sort of attachment to the various cultures they have experienced without being fully committed to any particular culture (Pollock \& Van Reken, 2009). These individuals combine components of the different cultures into their personal experiences. Consequently, they identify themselves with those who share comparable cultural encounters (Pollock \& Van Reken, 2009). The term adult third culture kids (ATCKs) refers to third culture kids who are over 18 years of age (Wisecarver, 2014). In addition to identification with the various cultures they lived in, TCKs also identify themselves with their parents' culture. This diverse cultural legacy is the major characteristic shared by TCKs. This rich cultural encounter leads them to the fusion of the values, beliefs and practices of the host countries and from their home countries to form their unique third culture (Carroll, 2019).

Current literature suggests that TCKs are prone to unresolved grief resulting from their continual movement from on country to another. TCKs, worldwide, are characterized by absence of cultural affiliation and a sense of cross-culturalism that may disturb their normal development (Keck, 2018). Problems encountered by TCKs include failure to establish close relationships, detachment, longing for home, and feelings of loss of family and belongings (Moore, 2011). Moreover, investigators also identified adjustment problems, anger (Bell-Villada, Sichel, Eidse \& Orr, 2011), uncertainty and grief (Keck, 2018) as factors that are related to cross-cultural living which refers to experiencing living in multiple or more than one culture (Kwon, 2018).

Studies have repeatedly shown that ATCKs lack skills necessary for establishing and sustaining healthy relationships (Reyal, 2015; Lijadi \& van Schalkwyk, 2014). Moreover, they often experience difficulties with relationships (Ozcan, 2015) and undergo identity confusion (Keck, 2018).

Cultural identity is linked to sense of belonging to, or identification with a particular group. This further depends on many factors such as sex, country of origin, ethnic group, religious affiliation, and racial background (Chen, 2014). Chen believes that cultural identity is shaped and preserved through social rules, heritage, and practices. $\mathrm{He}$ assumes that identity development proceeds through continuous execution, negotiation, challenge, and maintenance. It relies upon the circumstantial temporal and religious influencers within cultures (Chen, 2014). TCKs who experience frequent geographical transition may not develop strong identification with any particular culture, and hence, feel like they do not belonging to any specific culture (Devens, 2005).

The subject of identity confusion in TCKs has been the focus of many studies. Exposure to cultural influences during developmental years may cause confusion to TCKs which, further, may result in the formation of disintegrated identities (Vivero \& Jenkins, 1999). However, some studies have shown that TCKs either typically exhibit early maturity or delayed puberty (Pollock, Van Reken \& Pollock, 2017). An individual's personal identity develops within the context of his/her social interaction and cultural environment (Usborne \& de la Sablonnière, 2014). It becomes problematic when TCKs 
fail to identify themselves with a specific culture. This results in negative psychological experiences (Usborne \& de la Sablonnière, 2014).

Phinney, Romero, Nava \& Huang (2001) found that parents can induce constructive impacts on their kids' identity through vigorous endorsement of home culture. This can be done through discussing the importance of their unique ethnic background, their history, engendering ethnic and cultural pride, and enriching their kid's knowledge of home culture values, norms, and tradition.

Identity confusion among TCKs is linked to several issues, such as loyalty and devotion to home country, cultural ideals, and involvement in political activities (Wotjecka, 2017). TCKs find it difficult to resolve potential conflicts between the different cultures they live in, including their home culture. This conflict may negatively impact their loyalty to their home country and their relationships with fellow citizens (Pollock, et al., 2017). TCKs and ATCKs also expressed problems such as loss of friends and failure to establish close relationships, and reported experiencing depression (Hill, 2016).

It is estimated that over 264 million people worldwide are affected by depression (World Health Organization, 2020). Research has shown that gender differences in depression are not consistent. Some studies found no gender differences (Wenjuan, Siqing \& Xinqiao, 2020; Theeke, Carpenter, Mallow, \& Theeke, 2019), some found higher rates of depression among female students (Liu et al., 2019; Crockett, Martínez \& Jiménez-Molina, 2020) while other researchers found greater rates of depression among male students (Al-Qaisy, 2011).

Despite the lack of information concerning the rates of depression in the United Arab Emirates, the disorder is a well-known phenomenon in the region. TCKs frequently relocate to other cultures during their crucial developmental stages (Pollock \&Van Reken, 2009). Depression in TCKs may result from the lack of ability to perceive based on a single cultural perspective and failure to accomplish their developmental stages within one culture (Devens, 2005). TCKs are frequently separated from friends and extended family. This can generate distrust and failure to establish and maintain healthy attachment and bonding that, in turn, hinders the formation of subsequent close relations (Devens, 2005).

There are about 9 million migrants in U.A.E which represents $87.9 \%$ of the total population (UN, 2019). The kids of these migrants form a majority among kids in the United Arab Emirates. However, little is known about the precautionary measures required to protect these kids and to reduce their chances of developing mental health problems. There have been no previous studies that investigated depression and identity orientation among undergraduate ATCKs in UAE. While mental health services have witnessed significant improvements in the country, the TCKs group received little attention. The present study is expected to add to the current knowledge of difficulties encountered by TCKs through measuring identity orientation and the incidence of depressive symptoms amongst ATCKs studying at United Arab Emirates University (UAEU). A further rationale for selecting college students is the sensitivity of their developmental period. College students are mainly young adults and adolescents who are highly susceptible to culture shock which may result in mental health problems 
(Gaw, 2000). The present study is expected to shed some light on the problems experienced by ATCKs and the need for preventive and therapeutic measures.

Literature suggests that depression is on the rise within the country (Adams, M. 2016). Therefore, it is of paramount importance to examine this phenomenon among ATCKs. Further, the current study will enable mental health specialists in the UAE to better comprehend the difficulties experienced by adult third culture kids.

The aim of the present exploratory study is to investigate the importance of the different aspects of identity orientations to ATCKs, and to identify depressive symptoms amongst ATCKs studying at United Arab Emirates University. Additionally, this study will examine if gender and various aspects of identity orientation are related to and predict depressive symptoms.

It is hypothesized that: (1) ATCK participants will report high levels of depressive symptoms; (2) Some aspects of identity orientations will be more important to ATCKs than other aspects; (3) Identity orientations will predict depression in ATCKs

\section{METHOD}

\section{Participants}

Purposive sampling technique was used to select a sample of 250 migrant undergraduate students studying at the United Arab Emirates University. One hundred eighty-three $(73.2 \%)$ of the respondents were females, whereas $67(26.8 \%)$ were males. The respondents hailed from 35 different countries. About $105(42 \%)$ of the participants aged 18-20 years; 127 (50.8\%) aged 21-23 years; and 18 (7.2\%) aged 24-26 years. Two hundred thirty-three $(93.2 \%)$ of the respondents lived in U.A.E. throughout their childhood development stages (age 0-13 years), and the remaining 6.7\% resided in other countries during their developmental years; these countries include Saudi Arabia, U.S.A, Iran, Uzbekistan, Papua New Guinea, and U.K (n=1). Seventy-nine (31.6\%) of the respondents are in the College of Science, 57 (22.8\%) in the College of Humanities, 40 $(16 \%)$ in the College of Engineering, and $36(14.4 \%)$ in the College of Business and Economics. Only students who resided in countries other than their home countries during the age of 0-13 years were recruited to participate in the present study.

\section{Instruments}

Respondents were asked provide demographic information and rate themselves on two questionnaires. These are the Aspects of Identity Questionnaire (AIQ IV-45) and Beck Depression Inventory (BDI-II).

\section{Demographic Information}

Demographic information included the respondent's gender, age, native language, college, home country, country where the respondent was living during the first 13 years of his/her life, and country where the respondent resides at the time of the study. Some of these questions were used to ensure that the respondent meets the criteria for defining ATCKs. 
Aspects of Identity Questionnaire (AIQ IV-45; Cheek \& Briggs, 2013):

This questionnaire measures four different aspects of identity, namely: personal identity orientation (PI), relational identity orientation (RI), social identity orientation (SI), and collective identity orientation (CI). This questionnaire is scored on a 5-point Likert type scale ranging from 1 (not important to my sense of who I am) to 5 (extremely important to my sense of who I am). Respondents state the extent to which a statement is applicable by selecting the appropriate score given to each answer. Cronbach Alpha reliabilities in this study were $0.90(M=37.97, S . D=8.02)$ for PI; $0.89(M=35.88, S . D$ $=7.90)$ for RI; $0.82(M=21.72, S . D=5.71)$ for SI; and $0.79(M=25.10, S . D=6.52)$ for CI, respectively.

Beck's Depression Inventory (BDI-II, Beck, Steer \& Brown, 1996):

The BDI-II is a 21-item version that assesses depressive symptom within the last two weeks. The symptoms measured include, emotional, cognitive and behavioural symptoms of depression. (Khesht-Masjedi, Shokrgozar, Abdollahi, Mahbuobe Golshahi, \& Sharif-Ghaziani, 2017). This inventory is scored on a 4-point Likert type scale ranging from 0 (minimal) to 3 (severe). The total score ranges between 0 to 63 . The following criteria is used for the BDI-II: 0-13= minimal, $14-19=$ mild, $20-28=$ moderate, 29-63= severe (Beck et al., 1996). This inventory has been widely used in the United Arab Emirates for numerous research studies as well as in clinical practice. Hence, the validity and reliability of the BDI-II has been established in this particular region. The Alpha reliability for the total score in this study was $0.92(M=15.48, S . D=11.24)$.

\section{Procedure}

Ethical approval to conduct the study was obtained from the Social Sciences Research Ethics Committee (Ref No: ERS_2019_5879). The list of the ATCKs in the UAEU hostels was provided by the hostel administration and used to identify students in the hostels. The link to the online survey was emailed to respondents asking them to take part in the study. They were asked to sign a consent form prior to proceeding with the survey. Then, they choose 'Agree' if they are willing to participate in the study. The aims of the study and instructions showing how to answer the questions were clarified to the respondents. They were informed that participation in the study was voluntary and that they could withdraw from the study at any stage. Further, they were assured that the information they provide would be treated with high confidentiality and would only be used for the purpose of the study.

\section{Data analysis}

The Statistical Package for Social Science (IBM SPSS-26) was used to analyse the data. Descriptive statistics were performed to report the participants characteristics the incidence of depression, and aspects of identity orientations. Pearson correlation was run to test intercorrelations among the study variables. T-test was used to examine gender differences in depression and identity orientations, and ANOVA was conducted to determine age group differences in depression and identity orientations. Stepwise regression was run to test the ability of aspects of identity orientations to predict depressive symptoms. 


\section{FINDINGS}

description of depressive symptoms and aspects of identity:

As shown in Table $1,72.8 \%$ of the respondents reported minimal to mild depression, while $27.2 \%$ reported moderate to severe depression.

Table 1

Frequencies and percentages of depressive symptom assessed by BDI-II

\begin{tabular}{lll}
\hline Rating & Frequency & Percentage \\
\hline Minimal Depression & 13 & $5.2 \%$ \\
\hline Mild depression & 169 & $67.6 \%$ \\
\hline Moderate Depression & 31 & $12.4 \%$ \\
\hline Severe depression & 37 & $14.8 \%$ \\
\hline
\end{tabular}

About $59.6 \%$ of the respondents considered PI as extremely important to their sense of who they are; $44.8 \%$ considered RI to be extremely important to their sense of who they are; $26.8 \%$ considered SI to be extremely important to their sense of who they are; and 23.2 considered CI to be extremely important to their sense of who they are (See Table 2). PI seems to be the most extremely important to the sense of who the person is and CI the least extremely important.

Table 2

Description of aspects of Identity Orientations and their importance

\begin{tabular}{|c|c|c|c|c|}
\hline Identity Orientations & $M$ & $S D$ & Frequency & $\%$ \\
\hline Personal Identity Orientation PI & 37.97 & 8.02 & & \\
\hline Not important to my sense of who I am & & & 12 & $4.8 \%$ \\
\hline Somewhat important to my sense of who I am & & & 89 & $35.6 \%$ \\
\hline Extremely important to my sense of who I am & & & 149 & $59.6 \%$ \\
\hline Relational Identity Orientation RI & 35.88 & 7.90 & & \\
\hline Not important to my sense of who I am & & & 14 & $5.6 \%$ \\
\hline Somewhat important to my sense of who I am & & & 124 & $49.6 \%$ \\
\hline Extremely important to my sense of who I am & & & 112 & $44.8 \%$ \\
\hline Social Identity Orientation SI & 21.72 & 5.71 & & \\
\hline Not important to my sense of who I am & & & 44 & $17.6 \%$ \\
\hline Somewhat important to my sense of who I am & & & 139 & $55.6 \%$ \\
\hline Extremely important to my sense of who I am & & & 67 & $26.8 \%$ \\
\hline Collective Identity Orientation CI & 25.10 & 6.52 & & \\
\hline Not important to my sense of who I am & & & 30 & $12.0 \%$ \\
\hline Somewhat important to my sense of who I am & & & 162 & $64.8 \%$ \\
\hline Extremely important to my sense of who I am & & & 58 & $23.2 \%$ \\
\hline
\end{tabular}

Intercorrelation between the study variables:

Pearson correlation analysis showed that depression was positively correlated with social identity orientation only. Those who are high in social identity orientation reported more severe depressive symptoms. All 4 dimensions of identity orientations are positively related to each other (see Table 3) 
Table 3

Correlation between the study variables

\begin{tabular}{llllll}
\hline & 1 & 2 & 3 & 4 & 5 \\
\hline 1. BDI-II Total & - & - & - & - & - \\
\hline 2. PI & 0.075 & - & - & - & - \\
\hline 3. RI & 0.055 & $* * 0.701$ & - & - & - \\
\hline 4. SI & $* 0.152$ & $* * 0.514$ & $* * 0.584$ & - & - \\
\hline 5. CI & 0.040 & $* * 0.508$ & $* * 0.609$ & $* * 0.614$ & - \\
\hline Note $*$ P $<.05 * * * \mathrm{P}<01$ & & & &
\end{tabular}

Between group differences in depressive symptoms and identity orientations

T-tests were run to find out if gender has significant effects on depression and identity orientations. The results showed significant gender differences in depression $(\mathrm{t}=-3.272$, $\mathrm{df}=248, \mathrm{p}<$. 0.01). Female participant $(\mathrm{M}=16.939 ; \mathrm{SD}=11.227)$ reported more depression compared to male participants $(M=11.776 ; S D=10.560)$. There were no significant gender differences in identity orientation dimensions.

ANOVA was rung to test age differences in depression and identity orientations. The results of ANOVA showed no significant age differences in depression or identity orientation dimensions.

\section{Ability of gender and identity orientations to predict depression}

A stepwise multiple regression analysis was conducted to test the predictive ability of gender (as a dummy variable: 0 for female; 1 for male), PI, RI, SI and CI on depression. Stepwise regression was further administered to enable ranking predictors based on their significance. Gender and identity orientations were entered as predictor variables while depression was entered as the dependent variable. The results showed that only gender and social identity orientation significantly predicted depression scores (Table, 4). Gender explained $4.1 \%$ variance in depression, while Social identity predicted additional $2.5 \%$.

Table 4

Summary results of regression analysis

\begin{tabular}{lllllllll}
\hline Mode & $R$ & $R 2$ & $\begin{array}{l}R 2 \\
\text { change }\end{array}$ & $B$ & SE B & Beta & $\mathrm{t}$ & $\mathrm{p}$ \\
\hline $\begin{array}{l}\text { Model 1 } \\
\text { gender }\end{array}$ & .203 & .041 & .041 & -5.164 & 1.578 & -.203 & -3.272 & .001 \\
\hline $\begin{array}{l}\text { Model 2 } \\
\begin{array}{l}\text { Gender } \\
\text { SI }\end{array}\end{array}$ & .258 & .066 & .025 & & & & & \\
\hline
\end{tabular}

Note:

Model 1: $F(1,248)=10.704, \mathrm{p}<.0 .01$

Model 2: $\mathrm{F}(2,247)=8.788, \mathrm{p}<.0 .001$

\section{DISCUSSION}

This study was aimed to examine the incidence of depressive symptoms and dimensions of identity orientations among ATCKs studying at the UAEU, and to test whether 
identity orientations predict depression. Regarding the first hypothesis which postulates high prevalence of depressive symptoms, the findings indicated that $27.2 \%$ of the respondents reported moderate to severe depression (moderate depression 12.4\%; severe depression $=14.8 \%$ ) and $72.8 \%$ of them reported minimal to mild depressive symptoms. This supports the first hypothesis and Theeke et al.'s (2019) findings that showed similar prevalence rates of major depressive episode (17.7\%) and subthreshold depressive episode (16.5\%).

The findings of this study are in line with earlier research in recognizing unresolved grief and depressive symptoms in adult third culture kids (Keck, 2018) and third culture kids (Devens, 2005). Existing research has recognized many factors as triggers and causes of depressive symptoms among TCKs. These factors include identity confusion (Keck, 2018) persistent sense of detachment from family members and friends (Devens, 2005), and feelings of rootlessness (Vivero \& Jenkins, 1999). The bulk of the participants in the current study is from eastern cultures. The cultural norms, values, beliefs, and traditions they experience are dissimilar to that experienced in western cultures. Hence, future studies need to examine differences in cultural experiences prior to drawing any conclusions about the possible factors contributing to the high rate of depression among ATCKs in this study.

In the present study, personal and relational identity orientations emerged to be central to the respondents' sense of who they are, while collective and social identity orientations appeared to be less central. This supports the second hypothesis which suggests that some aspects of identity orientations, such as personal identity orientation, will be more important to TCKs than other aspects, such as collective Identity orientation. This result is congruent with existing literature which suggest that ATCKs encounter many problems, such cultural detachment, social alienation, failure to identify with a particular culture, homesickness, and tendency to relate to ATCKs who share similar circumstances (Pollock \& van Reken, 2009; Vivero \& Jenkins, 1999). Research has also shown that ATCKs are well- educated, self-oriented, and career-focused (Fail, Thompson \& Walker, 2004). Thus, our findings are in line with the results of previous studies in putting more emphasis on the value of relational and personal aspects of identity orientation, compared to collective and social aspects of identity orientation.

Our third hypothesis assumes that identity orientations will predict depressive symptoms in ATCKs. This hypothesis is partially supported. Only one of the four aspects of identity orientation, social identity orientation, appeared to be positively correlated with depressive symptoms, though only $26.8 \%$ of the respondents described it to be extremely important to their sense of who they are. This, possibly, suggests that higher levels of social identity justify an increase in depressive symptoms or vice versa. Individuals with more strong identity orientation tend to attend to social needs and expectations, and are expected to conform to social pressure and standards (Chen, 2014). Attempts to conform to social pressure could put the person under continuous strain which further explains why social identity is positively correlated to depressive symptoms. 
Gender predicted $4.1 \%$ of the variance in depression and social identity orientation predicted additional $2.5 \%$ of the variance. Female participants also reported more elevated levels of depression compared to male participants. Women may experience greater depression due to hormonal changes and chromosomal differences (Albert, 2015). Though small, these percentages are statistically significant. These results support the findings that revealed higher rates of depression among female students (Liu et al., 2019; Crockett et al., 2020). However, some researchers found greater rates of depression among male students (Al-Qaisy, 2011), while others found no gender differences (Wenjuan et al., 2020; Theeke et al., 2019).

\section{CONCLUSION}

The current study showed that depression is common among this sample of ATCKs university students, and that depressive symptoms and social identity orientation are interrelated. The ATCKS in the present mainly hail from Eastern pluralistic cultures and societies. These cultures greatly value conformity to social and cultural norms which may place the individual under immense strain. The results imply that policy makers should pay more attention to mental health problems encountered by ATCKs. Mental health professionals, families, educators, employers, and friends should be trained to better understand the ATCKs and the problems they encounter. Mass media and social media may be used to increase awareness about ATCKs and help reduce the adverse short-term and long-term impacts on the ATCKs.

Active efforts should be exerted to enable families and peers of ATCKs to distinguish between sadness and the unresolved grief experienced by ATCKs. As evident from previous research, ATCKs tend to identify with people with similar cultural experiences, or other ATCKs. Hence, upcoming research can investigate the efficacy of support group models in helping ATCKs to deal with the difficulties they face. In the U.A.E culture, mental health is excessively stigmatized. This issue may hinder ATCKs from seeking professional help.

\section{Limitations}

There are some limitations and caveats associated with the present study. The correlational design is considered a major drawback. Conclusions cannot be drawn about the potential causal relationships between identity orientations and depression given the cross-sectional nature of the study design. Longitudinal designs are needed to examine causality. Another limitation is that the data was collected through online selfreport measures. Online surveys are usually associated with low response rate. In addition, data obtained through online surveys could be inconsistent if the questionnaires are not responded to correctly. Interviews can be combined with surveys or used separately to acquire more accurate data. Furthermore, quantitative and qualitative methods of data collection can be mixed to obtain rich data. Then, the qualitative data may be coded into quantitative date or analysed independently. Additionally, our study did not investigate some vital characteristic of ATCKs, such as multicultural identity, coping skills, relational styles, and unresolved grief. Futures 
studies can examine these characteristics and other problems encountered by TCKs. Future studies also need to test the replicability of the findings of the present study.

\section{REFERENCES}

Adams, M. (2016). What you should know about mental health and the UAE workforce. Retrieved from https:// gulfbusiness.com/know-mental-health-uae- workforce/

Albert, T. R. (2015). Why is depression more prevalent in women? J Psychiatry Neurosci., 40, 219-221.doi: 10.1503/jpn.150205

Al-Qaisy, L.M., (2011). The relation of depression and anxiety in academic achievement among group of university students. Int. J. Psychol. Counsell. 3(5), 96-100.

Bell-Villada, G., Sichel, N, Eidse, F., \& Orr, E. (2011). Writing Out of Limbo: International Childhoods, Global Nomads and TCKs. New Castle, UK: Cambridge Scholars Publishing.

Carroll, M. (2019). How does growing up as a Third Culture Kid (TCK) impact life choices?: Effects on ATCKs and their educational and career experiences. (Master Thesis). DOI: 10.13140/RG.2.2.14544.76807

Chen, V. H. H. (2014). Cultural identity. Key Concepts in Intercultural Dialogue, 22. Retrieved from https://centerforinterculturaldialogue.files.wordpress.com/2014/07/keyconcept-cultural-identity.pdf

Crockett, M. A., Martínez, V., Jiménez-Molina, A. (2020). Subthreshold depression in adolescence: Gender differences in prevalence, clinical features, and associated factors. Journal of Affective Disorders, 272, 269-276.

Devens, J. A. (2005). Depression rates among third culture kids in an international school setting (Doctoral dissertation). Retrieved from https://search-proquest com.ezproxy.uaeu.ac.ae/docview/305360449?pq-origsite=summon.

Fail, H., Thompson, J., \& Walker, G. (2004). Belonging, identity and Third Culture Kids: Life histories of former international school students. Journal of Research in International Education, 3, 319-338. https://doi.org/10.1177/1475240904047358.

Gaw, K. F. (2000). Reverse culture shock in students returning from overseas. International Journal of Intercultural Relations, 24, 83-104.

Harvey, E. (2009). Cultural transitions during childhood and adjustment to college. Journal of Psychology and Christianity, 28(1), 3-12. Retrieved from https://www.researchgate.net/publication/288867322_Cultural_transitions_during_child hood_andadjustment_to_college/citation/download.

Hill, J. (2016, December 13). UAE's third-culture kids reveal what heritage means to them. The National. Retrieved from https://libguides.library.usyd.edu.au/c.php?g=508212\&p=3476096. 
Keck, B. (2018). Attachment, social support, and disenfranchised grief in adult third culture kids (Doctoral dissertation). Retrieved from https://search.proquest.com/openview/c7f9b9385c6133639bb277ad1a7232fc/1?pqorigsite $=$ gscholar $\& \mathrm{cbl}=18750 \&$ diss $=\mathrm{y}$

Khesht-Masjedi, M. F., Shokrgozar, S., Abdollahi, E, Mahbuobe Golshahi, M., \& Sharif-Ghaziani, Z. (2017). Comparing depressive symptoms in teenage boys and girls. Journal of Family Medicine and Primary Care, 6(4), 775-779. doi: 10.4103/jfmpc.jfmpc_129_17

Kwon, J. (2018): Third Culture Kids: Growing up with mobility and cross-cultural transitions, Diaspora, Indigenous, and Minority Education, DOI: 10.1080/15595692.2018.1490718

Liu, Y., Zhang, N., Bao, G., Huang, Y., Ji, B., Wu, Y., Liu, C., Li, G. (2019). Predictors of depressive symptoms in college students: a systematic review and meta-analysis of cohort studies. Journel of Affective Disorders, 244, 196-208.

Moore, A. (2011). Confused or multicultural: A phenomenological analysis of the selfperception of TCKs with regard to their cultural identity (MA thesis). Retrieved from http://digitalcommons.liberty.edu/cgi/viewcontent.cgi?article $=1167 \&$ context $=$ master.

Ozcan, M. 2017. Simulating a third culture kid experience to enhance friendship prospects in early interactions (Honors Thesis). Retrived from http://repository.wellesley.edu/thesiscollection/473.

Phinney, J. S., Romero, I., Nava, M., \& Huang, D. (2001). The Role of Language, Parents, and Peers in Ethnic Identity Among Adolescents in Immigrant Families. Journal of Youth and Adolescence, 30, 35-153.

Pollock, D. C., \& Van Reken, R. E. (2009). Third Culture Kids: Growing Up Among Worlds. London: Nicholas Brealey Publishing

Pollock, D. C., Van Reken, R. E., \& Pollock, M. V.(2017). Third Culture Kids: Growing Up Among Worlds ( $3^{\text {rd }}$ Ed.). London: Nicholas Brealey Publishing

Reyal, G. M. (2015). Global identity formation and current life choices: Adult third culture kids (Doctoral dissertation). Retrieved from https://search-proquestcom.ezproxy.regent.edu/pqdtglobal/docview/1655588349/CB18B8C318474ADDPQ/1? a ccountid $=13479$.

Theeke, L., Carpenter, R. D., Mallow, J., \& Theeke, E. (2019). Gender differences in loneliness, anger, depression, self-management ability and biomarkers of chronic illness in chronically ill mid-life adults in Appalachia. Applied Nursing Research, 45, 55-62.

United Nations, Department of Economics and Social Affairs (2019). Retrieved from https://www.un.org/development/desa/en/news/population/international-migrant-stock2019.html 
Usborne, E., \& de la Sablonnière, R. (2014). Understanding My Culture Means Understanding Myself: The Function of Cultural Identity Clarity for Personal Identity Clarity and Personal Psychological Well-Being. Journal for the Theory of Social Behaviour, 44(4), 436-458. DOI: 10.1111/jtsb.12061

Vivero, V. N., \& Jenkins, S. R. (1999). Existential hazards of the multicultural individual: Defining and understanding "cultural homelessness". Cultural Diversity and Ethnic Minority Psychology, 5, 6-26.

Wenjuan, C. G., Siqing, P., \& Xinqiao, L. (2020). Gender differences in depression, anxiety, and stress among college students: A longitudinal study from. Journal of Affective Disorders, 263, 292-300.

World Health Organization (2020). Depression. Retrieved from https://www.who.int/news-room/fact-sheets/detail/depression 